\title{
CFD-Entropy generation analysis of refrigerant-based nanofluids flow in a tube
}

\author{
Mohammed Zohud ${ }^{1}$, Ahmed Ouadha ${ }^{2, *}$, Redouane Benzeguir ${ }^{1}$ \\ ${ }^{1}$ Laboratoire de Carburants Gazeux et Environnement, Faculté de Génie Mécanique, Université des Sciences et de la Technologie \\ Mohamed Boudiaf d'Oran, Oran El-M'nouar, 31000 Oran, Algérie \\ ${ }^{2}$ Laboratoire des Sciences et Ingénierie Maritimes, Faculté de Génie Mécanique, Université des Sciences et de la Technologie Mohamed \\ Boudiaf d'Oran, Oran El-M'nouar, 31000 Oran, Algérie
}

\begin{abstract}
The present paper aims to numerically investigate the flow, heat transfer and entropy generation of some hydrocarbon based nanorefrigerants flowing in a circular tube subject to constant heat flux boundary condition. Numerical tests have been performed for 4 types of nanoparticles, namely $\mathrm{Al}_{2} \mathrm{O}_{3}, \mathrm{CuO}$, $\mathrm{SiO}_{2}$, and $\mathrm{ZnO}$ with a diameter equal to $30 \mathrm{~nm}$ and a volume concentration of $\varphi=5 \%$. These nanoparticles are dispersed in some hydrocarbon-based refrigerants, namely tetrafluoroethane (R134a), propane (R290), butane (R600), isobutane (R600a) and propylene (R1270). Computations have been performed for Reynolds number ranging from 600 to 2200 . The numerical results in terms of the average heat transfer coefficient of pure refrigerants have been compared to values obtained using correlations from the literature. The results show that the increase of the Reynolds number increases the heat transfer coefficient and decreases the total entropy generation.
\end{abstract}

Keywords: Nanorefrigerant; CFD; Heat transfer coefficient; Entropy generation; Pressure drop

\section{Nomenclature}

cp Specific heat, $\mathrm{J} \mathrm{kg}^{-1} \mathrm{~K}^{-1}$

$D \quad$ Tube diameter, $\mathrm{m}$

$h \quad$ Convective heat transfer coefficient, $\mathrm{W} \mathrm{m}^{-2} \mathrm{~K}^{-1}$

$k \quad$ Thermal conductivity, $\mathrm{W} \mathrm{m}^{-1} \mathrm{~K}^{-1}$

$L \quad$ Length of the tube, $\mathrm{m}$

$\dot{m} \quad$ Mass flow rate

$\mathrm{Nu} \quad$ Nusselt number

Pr Prandtl number

$q \quad$ Heat flux, $\mathrm{W} \mathrm{m}^{-2}$

$r \quad$ Radius, $\mathrm{m}$

Re Reynolds number

$S_{g e n}^{\prime \prime} \quad$ Entropy generation rate, $\mathrm{W} \mathrm{K}^{-1}$

$T \quad$ Temperature, $\mathrm{K}$

$u \quad$ Axial velocity, $\mathrm{m} \mathrm{s}^{-1}$

$v \quad$ Radial velocity, $\mathrm{m} \mathrm{s}^{-1}$

\section{Introduction}

The life and development of modern human societies are seriously disturbed by two major problems, namely the energy resources shortage and the global warming. Refrigeration and air conditioning systems, crucial for everyday life, highly contribute to the depletion of energy resources and the global warming potential. Indeed, $15 \%$ of the electrical energy produced in the world is consumed by these systems. In response to these problems, several manufacturers have opted for natural

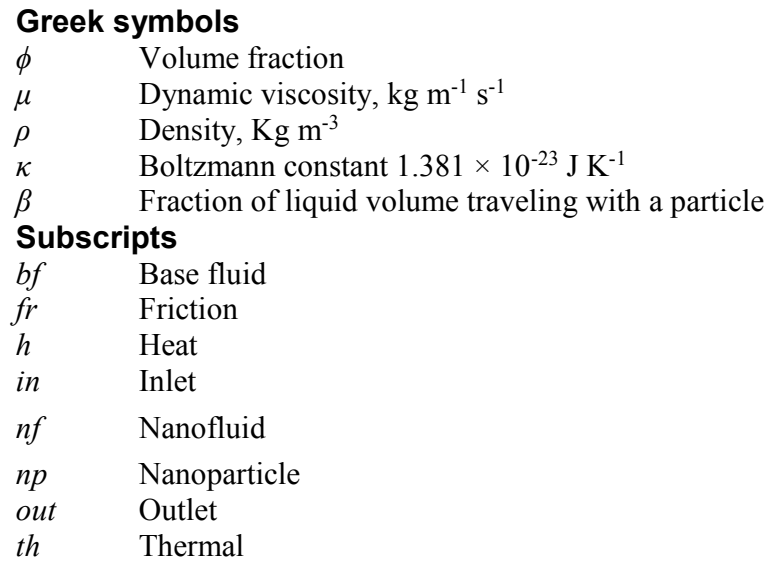

refrigerants such as ammonia, carbon dioxide and hydrocarbons to replace high global warming refrigerants. Further energy savings could be attained by the use of nanoparticles in refrigeration and air conditioning systems. Several studies have proved the enhancement of heat transfer characteristics by the use of nanoparticles dispersed in the refrigerant or the lubricating oil in refrigeration compressors [1-13]. On the other hand, according to Wang and Xie [14], nanoparticles enhance the solubility of the refrigerant in the lubricant. Furthermore, the dispersion of

\footnotetext{
Corresponding author: ah_ouadha@yahoo.fr
} 
nanoparticles in lubricants decreases the friction coefficient and wear rate [15-16].

The concept of nanofluids, demonstrated the first time by Choi [17], can be applied to refrigeration systems by mixing conventional refrigerants with nanoparticles to give nanorefrigerants. Nanofluids have proven substantial heat transfer enhancement in various applications such as solar collectors, desalination systems, refrigeration systems, etc.

The literature contains also some reviewing papers related to nanorefrigerants. The reviewed studies are reported and categorized in several topics including, properties of nanoparticles suspended in the nanorefrigerant and nanolubricants of refrigeration systems [18], flow characteristics an applications [19], fundamentals, preparation and applications of nanorefrigerants [20] and thermophysical properties and performance characteristics of a refrigeration system using refrigerant-based nanofluids [21]. Nanorefrigerants have been used by many researchers in refrigeration systems. For example, Padmanabhan and Palanisamy [22] have used $\mathrm{TiO} 2$ nanoparticles in a vaporcompression refrigeration system in order to decrease irreversibilities. $\mathrm{Bi}$ et al. [11] have investigated experimentally the use of $\mathrm{TiO}_{2}-\mathrm{R} 600$ a nano-refrigerants in a domestic refrigerator without any system reconstruction. Their results indicate that $\mathrm{TiO}_{2}-\mathrm{R} 600 \mathrm{a}$ nano-refrigerants work normally and safely in the refrigerator and that the refrigerator performance was better than the pure R600a system, with 9.6\% less energy used with $0.5 \mathrm{~g} / \mathrm{L}$ TiO2-R600a nano-refrigerant. Azmi et al. [23] have carried out a comprehensive review to investigate the impact of nanorefrigerant and nanolubricant on energy saving. The overview consists of properties enhancement of nanorefrigerant and nanolubricant, tribological performance, heat transfer enhancement, performance in heat exchanger, improvement in refrigeration system and pressure drop characteristic. Their results showed that the best energy saving with $21 \%$ less energy used was with the use of $0.5 \%$ volume $\mathrm{ZnO}-\mathrm{R} 152 \mathrm{a}$ refrigerant nanolubricant. Both the suction pressure and discharge pressure were brought down by $10.5 \%$ when nanorefrigerant was utilized. The evaporator temperature was lessened by $6 \%$ with the utilization of nanorefrigerant. Yang et al. [24] have experimentally studied the heat transfer and flow characteristics of MWCNT-R141b nanorefrigerant with different mass fractions. Their results showed that the stability of MWCNT-R141b nanorefrigerant, which is the added dispersant, was good during the experiments. The $0.3 \mathrm{wt} \%$ MWCNT-R141b nanorefrigerants had optimal heat transfer enhancement effects compared with pure refrigerants. The maximum Nusselt number increased by $40 \%$. The specific pressure drop of the nanorefrigerant increased as the Reynolds number increased, and the specific pressure drop of the pure refrigerant was minimum, which is similar to R141b. Sun and Yang [25] have experimentally studied the flow boiling heat transfer characteristics of four nanorefrigerants (Cu-R141b, Al-R141b, $\mathrm{Al}_{2} \mathrm{O}_{3}-\mathrm{R} 141 \mathrm{~b}$, and $\mathrm{CuO}-\mathrm{R} 141 \mathrm{~b}$ ) in an internal thread copper tube. Results showed that the maximum heat transfer coefficient of the four kinds of nanorefrigerant increased by $17-25 \%$, the average heat transfer coefficient increased by $3-20 \%$, and the maximum heat transfer coefficient of $\mathrm{Cu}-\mathrm{R} 141 \mathrm{~b}$ nanorefrigerant increased by $25 \%$. They showed also that the design of efficient thermodynamic processes conserves the useful energy. A real energy conversion process is irreversible and accompanied by an increase in entropy, leading to a decrease in the available energy. Although that energy is conserved, according to the first law, the quality of the energy is decreased because energy is converted into a different form of energy. Thus, reducing entropy generated in a process will result in a more efficient design of energy the system. Since its establishment in [26], entropy generation minimization has become a topic of great interest in the thermo-fluid area. In his work, Bejan has combined the concept of fluid flow and heat transfer with the second law of thermodynamics in order to carry out an entropy generation minimization at the system component level. Relatively, few studies have been devoted to the entropy generation of nanofluids flow in tubes. For example, Singh et al. [27] theoretically investigated the entropy generated during the flow of $\mathrm{Al}_{2} \mathrm{O}_{3}$-water nanofluid in microchannels, minichannels, and conventional channels under laminar and turbulent regimes. Li and Kleinstreuer [28] numerically studied the entropy generation of $\mathrm{CuO}$-water nanofluid in trapezoidal microchannels. Moghaddami et al. [29] presented an estimation of the entropy generation of $\mathrm{Al}_{2} \mathrm{O}_{3}$-water and $\mathrm{Al}_{2} \mathrm{O}_{3} 3$-EG nanofluids in a circular tube under both laminar and turbulent flows using a constant heat flux boundary condition. Leong et al. [30] studied the entropy generation of $\mathrm{TiO}_{2}$-water and $\mathrm{Al} 2 \mathrm{O} 3$-water nanofluids flows in a circular tube with a wall at constant temperature. Anand [31] analytically investigated the entropy generation of $\mathrm{Al}_{2} \mathrm{O}_{3}$-water and $\mathrm{Al}_{2} \mathrm{O}_{3}$-ethylene glycol flowing in a tube immersed in an isothermal fluid for Reynolds numbers up to 4500. They showed that particle loading is not advantageous from the second law viewpoint at high Reynolds numbers and the base fluid with high viscosity. Ebrahimi et al. [32] found that entropy generation can be reduced using nanofluids in microchannel heat sinks with rectangular cross-section and equipped with vortex generators. Ibáñez et al. [33] minimized the entropy generation due to $\mathrm{Al}_{2} \mathrm{O}_{3}$-water nanofluid in a porous microchannel under magnetohydrodynamic flow by considering thermal radiation, suction and injection, and slip flow.

Synthetic refrigerants such as R134a and R410a which are widely used in refrigeration and air conditioning systems are harmful gases themselves. Their global warming potential (GWP) is very high and are considered as strong global warming gases. Several programs aiming to phase down the production and commercialization of HFC-based refrigerants have been developed around the world. Compared to these refrigerants, in addition to their excellent thermodynamic properties, hydrocarbons are environmental friendly natural working fluids, which have zero ozone depleting potential (ODP) and negligible global warming potential $($ GWP $<20)$ as shown in Table 1 . They are also nontoxic, inexpensive and abundant. Used in a good design 
with some cautions due to their status as ASHRAE-rated high flammable (A3) refrigerants, hydrocarbons can be energy efficient, environmental friendly and used safely. It is demonstrated that some hydrocarbons such as propane and isobutane have similar or better performance compared to HFC-based refrigerants [3435].

Table 1. Refrigerant properties [36]

\begin{tabular}{lccccc}
\hline Properties & R134a & R290 & R600 & R600a & R1270 \\
\hline Molecular mass $(\mathrm{g} / \mathrm{mol})$ & 102.03 & 44.10 & 58.12 & 58.12 & 42.08 \\
Boiling point $\left({ }^{\circ} \mathrm{C}\right)$ & -26.1 & -42.1 & -0.5 & -11.7 & -47.7 \\
Critical temperature $\left({ }^{\circ} \mathrm{C}\right)$ & 101.1 & 96.7 & 131.2 & 152.0 & 92.4 \\
Critical pressure $(\mathrm{MPa})$ & 4.06 & 4.25 & 3.80 & 3.63 & 4.66 \\
Safety group & $\mathrm{A} 1$ & $\mathrm{~A} 3$ & $\mathrm{~A} 3$ & $\mathrm{~A} 3$ & A3 \\
GWP & 1430 & $\sim 20$ & $\sim 20$ & $\sim 20$ & $\sim 20$ \\
\hline
\end{tabular}

model has been successfully checked in several studies

Although there are several studies on nanofluids, studies related to nanorefrigerants are scarce. Hence, investigations on these types of nanofluids where the base fluid is a pure refrigerant are highly needed to determine and compare their flow and heat transfer characteristics. This aim can be achieved using numerical simulations which can, in some cases, minimize and direct tests on real models by guiding experimental research and equipment development. This study reports several numerical results of laminar forced convection of incompressible nanorefrigerants in a stainless steel tube.

\section{Mathematical Modeling and Simulation Method}

\subsection{Description of the problem}

A schematic representation of the tube configuration is shown in Fig. 1. The nanorefrigerant flows through a tube of $1 \mathrm{~m}$ length and $10 \mathrm{~mm}$ diameter. The nanorefrigerant enters the tube with a constant temperature and uniform velocity. A constant heat flux of $1000 \mathrm{~W} / \mathrm{m} 2$ is imposed at the tube wall.

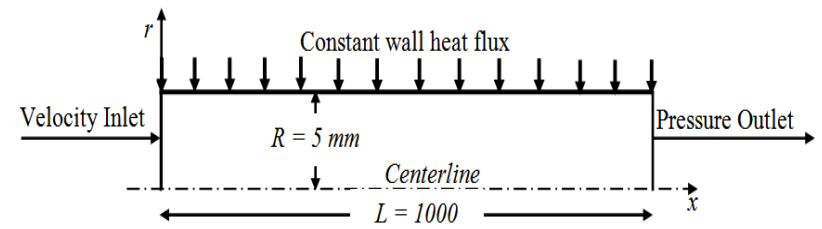

Fig. 1. Schematic representation of the physical domain with the dimensions and boundary conditions

\subsection{Governing equations and boundary conditions}

The simulation and prediction of the flow and heat transfer characteristics of nanorefrigerants is of critical importance for the efficient design and performance of heat exchangers. Generally, two numerical approaches are used in modeling the flow and heat transfer of nanofluids: the single-phase and the two-phase models. For the first model, the nanofluid is treated as a homogeneous fluid as the nanoparticles diameter $(\leq 100$ $\mathrm{nm})$ can be compared to the base fluid molecules diameter. Thus, it is assumed that the base fluid and the nanoparticles $(\varphi \leq 6 \%)$ are in thermal equilibrium with zero relative velocity between the two phases. This [37-39]. Supporters of the two-phase models proved that these models can give more realistic results compared to the single-phase model. They provide more accurate results with significant information on the distribution of nanoparticles within the base fluid [40-45].

In the present paper, the single-phase model is adopted where the governing equations are composed of conservation laws written for the mixture. For a laminar flow, they are given by the following equations:

$$
\begin{gathered}
\nabla \cdot\left(\rho_{n f} \dot{V}\right)=0 \\
\nabla \cdot\left(\rho_{n f} \vec{V} \vec{V}\right)=-\nabla p+\nabla \cdot\left(\mu_{n f} \nabla \vec{V}\right) \\
\nabla \cdot\left(\rho_{n f} \vec{V} c_{p_{n f}} T\right)=\nabla \cdot\left(k_{n f} \nabla T\right)
\end{gathered}
$$

where $\rho_{n f}, \mu_{n f}, c_{p n f}$ and $k_{n f}$ denote the nanofluid density, viscosity, specific heat and thermal conductivity respectively.

The accuracy of the results obtained using the singlephase model depends on the correlations used to calculate the nanofluid properties. In the present study, the commonly used correlations for the density [46], the specific heat [46], the dynamic viscosity [47] and the thermal conductivity [48] of nanofluids have been used:

$$
\begin{gathered}
\rho_{n f}=(1-\phi) \rho_{b f}+\phi \rho_{p} \\
c_{p n f}=(1-\phi) c_{p b f}+\phi c_{p p} \\
\mu_{n f}=\frac{\mu_{b f}}{(1-\phi)^{2.5}} \\
k_{n f}=k_{b f} \frac{k_{p}+2 k_{b f}+2 \phi\left(k_{p}-k_{b f}\right)}{k_{p}+2 k_{b f}-\phi\left(k_{p}-k_{b f}\right)} \\
+5.10^{4} \phi \beta \rho_{b f} c_{p b f} \sqrt{\frac{\kappa T}{\rho_{p} d_{p}}} f(T, \phi)
\end{gathered}
$$

where,

$$
\begin{aligned}
f(T, \phi)=( & \left.2.8217 \times 10^{-2} \phi+3.917 \times 10^{-3}\right)\left(\frac{T}{T_{0}}\right) \\
+ & \left(-3.0669 \times 10^{-2} \phi-3.91123 \times 10^{-3}\right)
\end{aligned}
$$

where $\kappa=1.381 \times 10^{-23} \mathrm{~J} / \mathrm{K}$ is the Boltzmann constant, $T_{0}$ a reference temperature fixed to $273.15 \mathrm{~K}$ and $\beta$ is the fraction of liquid volume traveling with a particle. 
Table 2. Correlations of $\beta$ for every type of nanoparticles [48-49]

\begin{tabular}{lccc}
\hline Particles & Correlation & Concentration & Temperature \\
\hline $\mathrm{Al}_{2} \mathrm{O}_{3}$ & $\beta=8.4407(100 \phi)^{-1.07304}$ & $1 \% \leq \phi \leq 10 \%$ & $298 \mathrm{~K} \leq \mathrm{T} \leq 363 \mathrm{~K}$ \\
$\mathrm{CuO}$ & $\beta=9.881(100 \phi)^{-0.9446}$ & $1 \% \leq \phi \leq 6 \%$ & $298 \mathrm{~K} \leq \mathrm{T} \leq 363 \mathrm{~K}$ \\
$\mathrm{SiO}_{2}$ & $\beta=1.9526(100 \phi)^{-1.4594}$ & $1 \% \leq \phi \leq 10 \%$ & $298 \mathrm{~K} \leq \mathrm{T} \leq 363 \mathrm{~K}$ \\
$\mathrm{ZnO}$ & $\beta=8.4407(100 \phi)^{-1.07304}$ & $1 \% \leq \phi \leq 7 \%$ & $298 \mathrm{~K} \leq \mathrm{T} \leq 363 \mathrm{~K}$ \\
\hline
\end{tabular}

As depicted in Fig. 1, a uniform velocity boundary condition $U$ depending on the value of the flow Reynolds number, a temperature of $300 \mathrm{~K}$ are specified at the inlet of the tube:

$$
\begin{gathered}
u(0, r)=U, \quad v(0, r)=0 \\
T(0, r)=300 K
\end{gathered}
$$

No-slip boundary conditions at the wall are imposed:

$$
u(x, R)=v(x, R)=0
$$

For all runs, a constant and uniform heat flux of 1000 $\mathrm{W} / \mathrm{m}^{2}$ is imposed at the tube wall:

$$
-\left.k_{n f} \frac{\partial T}{\partial r}\right|_{r=R}=1000 \mathrm{~W} / \mathrm{m}^{2}
$$

The Reynolds number is taken in the range between 600 and 2200. At the outlet of the tube, a zero gauge pressure is imposed.

The local heat transfer coefficient is calculated using:

$$
h(x)=\frac{q^{\prime \prime}}{T(x)_{w}-T(x)_{n f}}
$$

where $T(x)_{w}$ denotes the wall temperature as function of the tube location $\mathrm{x}$. it is calculated using

$$
T(x)_{w}=T(x, R)
$$

$T(x)_{n f}$ is the fluid mean temperature function of the tube location $\mathrm{x}$, which can be determined by:

$$
T(x)_{n f}=\int_{0}^{R} u r T d r / \int_{0}^{R} u r d r
$$

where $u$ is the axial velocity.

The average convection heat transfer coefficient is determined using

$$
h_{\text {avg }}=\frac{1}{L} \int_{0}^{L} h(x) d x
$$

The average Nusselt number is given by

$$
N u_{a v g}=\frac{h_{a v g} D}{k_{n f}}
$$

The thermodynamic optimization of any process can be achieved using the entropy generation minimization technique. Entropy can be used to quantify irreversibilities in processes. It is a measure of the level of energy quality and the destruction of the available work of the system. The intensity of irreversibility is measured using the concept of entropy generation. Thermodynamic imperfections and fluid flow irreversibilities can be reduced using the entropy generation minimization method.
To evaluate the benefits of hydrocarbons based nanorefrigerants from a thermodynamic point of view, the total entropy generation rate is used. It is defined as the sum of entropy generation rate due to friction and entropy generation rate due to heat transfer:

$$
S_{g e n}^{\prime \prime}=S_{g e n, h}^{\prime \prime}+S_{g e n, f}^{\prime \prime}
$$

The local volumetric entropy generation rate can be expressed for two dimensional flow as

$$
\begin{aligned}
& S_{\text {gen }}^{\prime \prime}=\frac{k}{T^{2}}\left[\left(\frac{\partial T}{\partial x}\right)^{2}+\left(\frac{\partial T}{\partial r}\right)^{2}\right] \\
& +\frac{\mu}{T}\left[2\left(\left(\frac{\partial u}{\partial x}\right)^{2}+\left(\frac{\partial v}{\partial r}\right)^{2}\right)+\left(\frac{\partial u}{\partial r}+\frac{\partial v}{\partial x}\right)^{2}\right]
\end{aligned}
$$

The first term on the right-hand side is the entropy generation due to heat transfer, while the second term is the entropy generation due to viscous dissipation.

\subsection{Numerical procedure}

Fig. 2 shows a cross-sectional view of the mesh of the tube. The mesh has been refined in the near-wall regions to capture the large gradients in the viscous boundary layer. The first mesh cell off the wall is specified to have a thickness of $0.07 \mathrm{~mm}$, then the cell thickness gradually increases away from the wall.

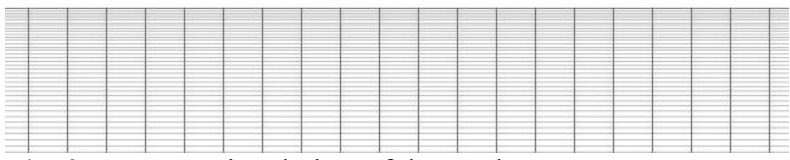

Fig. 2. Cross-sectional view of the mesh

The continuity, momentum, energy and turbulence equations for the above mentioned boundary conditions have been solved using the commercial CFD code Fluent. All computations have been performed in steady mode. Second order upwind discretization schemes are used for the convective terms in the momentum and energy equations, and the pressure-velocity coupling is ensured using the SIMPLE algorithm. The convergence criteria were $10^{-6}$ for all the variables. The thermophysical properties of nanoparticles and liquidphase refrigerants at $T=300 \mathrm{~K}$ are given in Table 3 .

\section{Results and Discussions}

The simulation results of the flow of hydrocarbons based nanorefrigerants in a horizontal circular tube subjected to a constant and uniform heat flux in a laminar flow are presented in this section. The results are presented for four types of nanoparticles, namely $\mathrm{Al}_{2} \mathrm{O}_{3}, \mathrm{CuO}, \mathrm{SiO}_{2}$ and $\mathrm{ZnO}$ dispersed in four kinds of pure hydrocarbon 
refrigerants (R134a, R290, R600, R600a and R1270). The computations have been carried out for particle volumetric concentrations of 5\% and Reynolds number ranging from 600 to 2200 . For all runs the particles diameter has been fixed to $30 \mathrm{~nm}$. Nanorefrigerants considered in the present study have been compared in terms of average convective heat transfer coefficient, pressure drop and entropies due to heat transfer and to friction.

Table 3. Thermophysical properties of nanoparticles and liquid-phase refrigerants at $T=300 \mathrm{~K}$ [50-52]

\begin{tabular}{|c|c|c|c|c|c|c|}
\hline & & $p(\mathrm{MPa})$ & $\rho\left(\mathrm{kg} \mathrm{m}^{-3}\right)$ & $c_{p}\left(\mathrm{~J} \mathrm{~kg}^{-1} \mathrm{~K}^{-1}\right)$ & $k\left(\mathrm{~W} \mathrm{~m} \mathrm{~m}^{-1} \mathrm{~K}^{-1}\right)$ & $\mu \times 10^{-5}\left(\mathrm{~kg} \mathrm{~m}^{-1} \mathrm{~s}^{-1}\right)$ \\
\hline \multirow{5}{*}{ 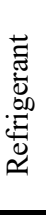 } & $\mathrm{R} 134 \mathrm{a}$ & 0.70282 & 1199.7 & 1432 & 0.0803 & 19.05 \\
\hline & R290 & 0.99780 & 489.5 & 2748 & 0.0929 & 9.53 \\
\hline & R600a & 0.37000 & 548.3 & 2442 & 0.0886 & 14.82 \\
\hline & R600 & 0.25760 & 570.7 & 2451 & 0.1039 & 15.56 \\
\hline & $\mathrm{R} 1270$ & 1.21212 & 501.2 & 2692 & 0.1098 & 9.284 \\
\hline \multirow{4}{*}{ 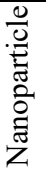 } & $\mathrm{Al}_{2} \mathrm{O}_{3}$ & - & 3600 & 765 & 36 & - \\
\hline & $\mathrm{CuO}$ & - & 6500 & 533 & 17.65 & - \\
\hline & $\mathrm{SiO}_{2}$ & - & 2200 & 745 & 1.4 & - \\
\hline & $\mathrm{ZnO}$ & - & 5600 & 495.2 & 13 & - \\
\hline
\end{tabular}

\subsection{Mesh sensitivity}

A mesh study has been performed in order to ensure the independency of the solution to the size of the mesh used. Five different structured meshes have been used: $10 \times 500,20 \times 1000,30 \times 1500,40 \times 2000$ and $50 \times 2500$. All runs have been carried out for R134a. Table 3 shows the results in terms of the average heat transfer coefficient.
A quick look reveals that the relative error between two meshes in predicting the heat transfer coefficient decreases with the increase of the mesh size. A relative error of $0.013 \%$ for the heat transfer coefficient is judged acceptable. Hence, the mesh $40 \times 2000$ has been selected for the analysis of the flow of all fluids in the tube.

Table 4. Mesh independency study

\begin{tabular}{ccc}
\hline Number of cells & $h_{\text {avg }}\left(\mathrm{Wm}^{-2}\right)$ & $\delta(\%)$ \\
\hline $10 \times 500$ & 62.229 & 0.723 \\
$20 \times 1000$ & 61.779 & 0.105 \\
$30 \times 1500$ & 61.714 & 0.031 \\
$40 \times 2000$ & 61.695 & 0.013 \\
$50 \times 2500$ & 61.687 & - \\
\hline
\end{tabular}

\subsection{Numerical model validation}

In absence of appropriate experimental data for hydrocarbons based nanorefrigerants, the computed results in terms of heat transfer coefficient have been compared to those obtained using empirical correlations developed by Seider and Tate [53] and Shah and London [54].

Seider and Tate [53] have developed a correlation allowing the determination of the average Nusselt number of several fluids. It is given by the following expression:

$$
N u_{a v g}=1.86\left(\operatorname{RePr} \frac{D}{L}\right)^{1 / 3}\left(\frac{\mu_{b}}{\mu_{w}}\right)^{0.14}
$$

where the dynamic viscosity for bulk fluid $(\mu \mathrm{b})$ and for the wall $\left(\mu_{w}\right)$ have been correlated as function of temperature to available data from the literature for each refrigerant.

Another correlation developed by Shah and London [54] allows the calculation of the Nusselt number using

$$
N u_{\text {avg }}=1.953\left(\operatorname{RePr} \frac{D}{L}\right)^{1 / 3}
$$

Fig. 3 exhibits a comparison between the heat transfer coefficient results obtained by the numerical model and those calculated using the correlations cited above for all refrigerants considered in the present study. It is noted that all refrigerants studied exhibit the same behavior, i.e. the increase of the Reynolds number increases the average heat transfer coefficient. The numerical results of the heat transfer coefficient as function of the Reynolds number are in good agreement with the results obtained using the correlation cited above. The difference between the two types of data enlarges for higher Reynolds number. It is interesting to note that the computed results deviates from those obtained from the correlation of Seider and Tate [53] with a mean error less than $4.1 \%$. The latter is greater for Shah and London [54]. It reaches $5.6 \%$.

\subsection{Comparative assessment of base refrigerants}

Prior to a series of nanorefrigerants runs, pure refrigerants flow simulations have been performed in order to determine the best substitute of R134a in terms of fluid, heat transfer and entropy generation characteristics. In Fig.4, at first glance, all hydrocarbon refrigerants perform better than R134a in terms of heat transfer and entropy generation. R600 performs the best, 
followed, in order, by R1270, R600a and R290. However, butane and isobutane present higher pressure drop compared to R134a, while the values for R290 and R1270 are clearly lower. As the thermal conductivity of R600 and R1270 is higher than that of the others refrigerants, their heat transfer characteristics are better. Further, refrigerants with higher effective viscosity produce higher pressure drop values. Consequently, taking into account both the heat transfer coefficient and pressure drop, R1270 boasts the best.

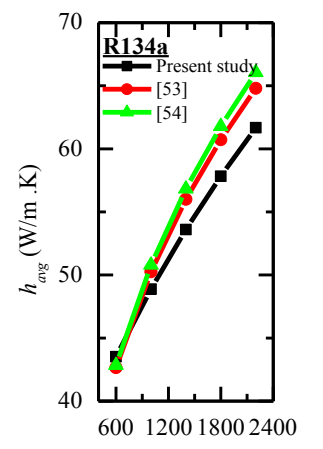

$R e$

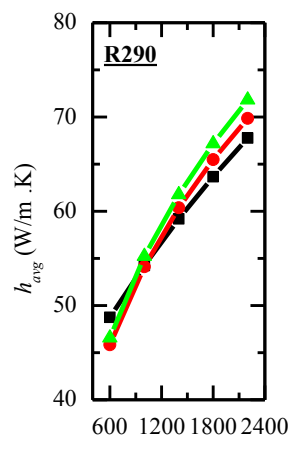

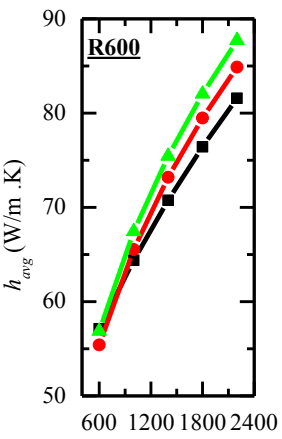

Re

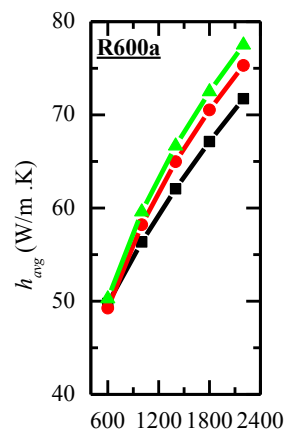

Re

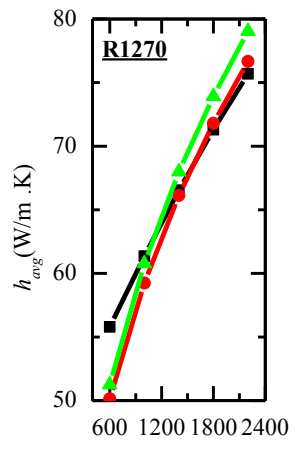

$\operatorname{Re}$

Fig. 3. Comparison of numerical average heat transfer coefficient of refrigerants with correlations from the literature

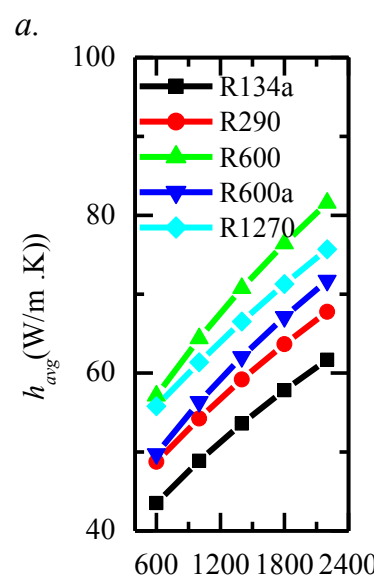

$R e$ b.

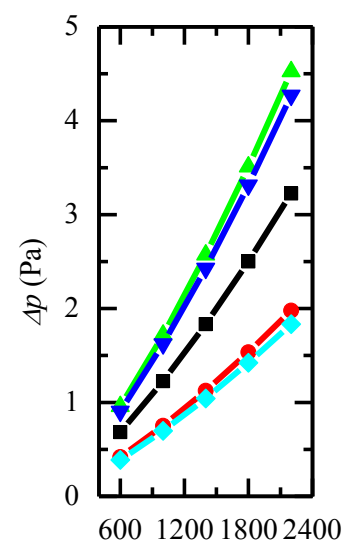

$R e$ $c$.

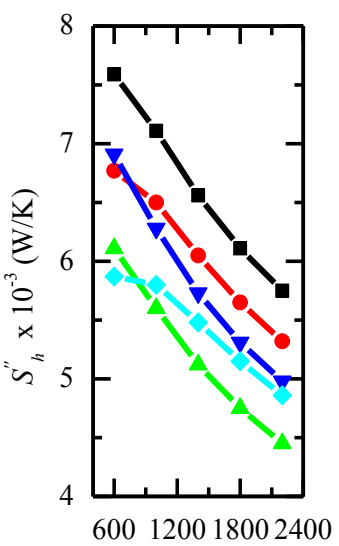

Re

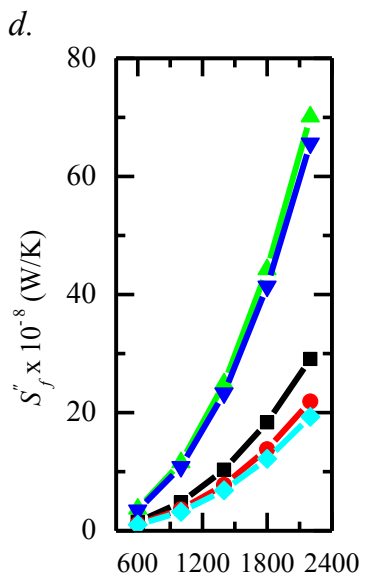

$R e$

Fig. 4. Comparison of base refrigerants: $a$. average heat transfer coefficient; $b$. pressure drop; $c$. thermal entropy generation rate; $d$. frictional entropy generation rate

\subsection{Propylene based nanorefrigerants}

Fig. 5.a illustrates the variation of the average heat transfer coefficient as function of the Reynolds number of propylene in the tube using the four types of nanoparticles, namely $\mathrm{Al}_{2} \mathrm{O}_{3}, \mathrm{CuO}, \mathrm{SiO}_{2}$ and $\mathrm{ZnO}$ with a volumetric concentration $5 \%$ and a nanoparticle diameter of $30 \mathrm{~nm}$. For all nanoparticles, the increase of the Reynolds number yields to an increase of the average heat transfer coefficient. It can be observed also that $\mathrm{Al}_{2} \mathrm{O}_{3}$ and $\mathrm{CuO}$ exhibits the higher heat transfer coefficient values, followed in order by $\mathrm{SiO}_{2}$ and $\mathrm{ZnO}$.

Fig. 5.b shows the variation of the pressure drop as function of the Reynolds number. Obviously, the pressure drop increases as the Reynolds number is increased. This increase is mainly due to the increase of velocity inside the tube. The dispersion of $\mathrm{SiO}_{2}$ in propylene provokes the highest pressure drop, followed in order by $\mathrm{Al}_{2} \mathrm{O}_{3}, \mathrm{ZnO}$ and $\mathrm{CuO}$.

Fig. 5.c and $d$ illustrate the variation of the entropy generation rate component as function of the Reynolds number for the four nanoparticles considered in the present study. In general, the increase of the Reynolds number involves a diminution of the entropy generation rate due to heat transfer and a rise of the entropy generation rate due to friction. On one hand, the increase of the Reynolds number improves the heat transfer mechanism between the tube wall and the fluid. On the other hand, the increase of the Reynolds number yields to higher velocity gradients which increase the entropy generation rate due to friction.

\section{Conclusion}

In the present study, the flow, heat transfer and entropy generation of some hydrocarbon based nanorefrigerants flowing in a circular tube subject to a constant heat flux boundary condition has been investigated. The main conclusions are raised below:

- Among all hydrocarbon refrigerants tested, propylene performs the best in terms of heat transfer and pressure drop characteristics.

- $\mathrm{CuO}$ as nanoparticle and 5\% volumetric concentration are the most suitable thanks to its high thermal and fluid characteristics. 
$a$.

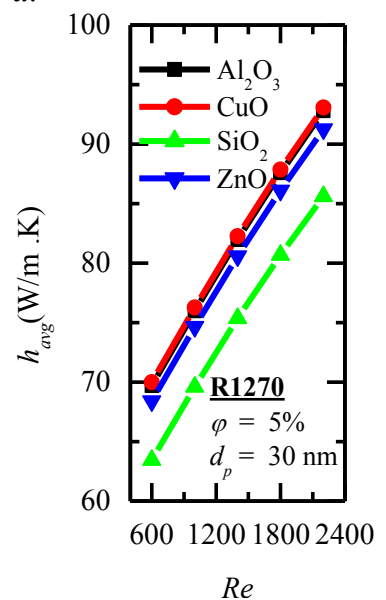

$b$.

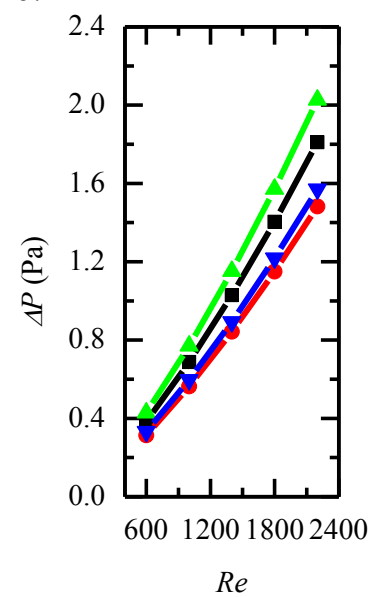

c.

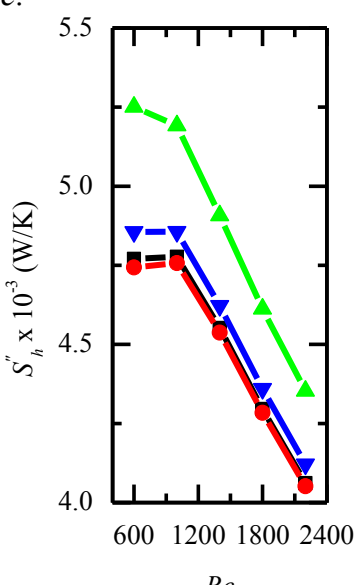

$d$.

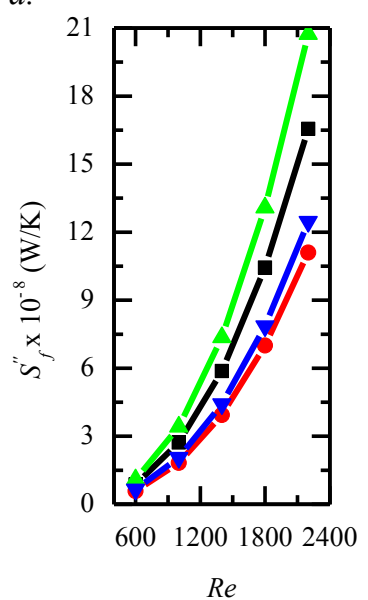

Fig. 5. Comparison of base refrigerant R1270 using the four types of nanoparticles: $a$. average heat transfer coefficient; $b$. pressure drop; $c$. thermal entropy generation rate; $d$. frictional entropy generation rate

\section{References}

1. S.S. Bi, H.L. Yong, L. Shi, 5th Int. Conf. proc., (2005)

2. K. J. Wang, G. L. Ding, W. T. Jiang, 4th Symposium on Refrig. Air Cond., Southeast University. (2006)

3. K. Park, D. Jung, Energy Building, 39, (2007)

4. X. M. Wu, P. Li, H. Li, W. C. Wang, J. Eng. Thermophys., 28, (2008)

5. S.S. Bi, J.T. Wu, L. Shi, J. Eng. Thermophys., 29, (2008)

6. W. Jiang, G. Ding, H. Peng, Int. J. Therm. Sci., 48, (2009)

7. H. Peng, G. Ding, W. Jiang, H. Haitao, Y. Gao, Int. J. Refrig., 32, (2009)

8. G. Ding, H. Peng, W. Jiang, Y. Gao, Int. J. Refrig., 32, (2009)

9. S. Bobbo, L. Fedele, M. Fabrizio, S. Barison, S. Battiston, C. Pagura, Int. J. Refrig., 33, (2010)

10. P. Hao, D. Guoliang, H. Haitao, J. Weiting, Z. Dawei, W. Kaijiang, Int. J. Refrig., 33, (2010)

11. S. Bi, K. Guo, Z. Liu, J. Wu, Energy Conv. Manag., 52, (2011)

12. M. Mahbubul, R. Saidur, M. A. Amalina, Int. J. Mech. Mater Eng., 7, (2012)

13. M. Mahbubul, R. Saidur, M. A. Amalina, Int. Commu. Heat Mass Transf., 43, (2013)

14. R. X. Wang, H. B. Xie, $4^{\text {th }}$ Int. Symposium on HVAC, Tsinghua University. (2003)

15. K. Lee, Y. Hwang, S. Cheong, L. Kwon, S. Kim, J. Lee, Curr. Appl. Phys., 9, (2009)

16. C.S. Jwo, L.Y. Jeng, T.P. Teng, H. Chang, J. Vac. Sci. Technol, 27, (2009)

17. S. Choi, Siginer DA, Wang HP (eds), FED-vol 231/MD-vol 66. ASME, New York, (1995)

18. R. Saidur, S. N. Kazi, M. S. Hossain, M. M. Rahman, H. A. Mohammed, Renew. Sust. Energy. Rev., 15, (2011)

19. A. Celen, A. Çebi, M. Aktas, O. Mahian, A.S. Dalkilic, S. Wongwises, Int. J. Refrig., 44, (2014)

20. O.A. Alawi, N.A.C. Sidik, H.A. Mohammed, Int. Commu. Heat Mass Transf. 54, (2014)
21. M. S. Patil, S. C. Kim, J. H. Seo, M. Y. Lee, Energies, 9, (2016)

22. V. M. V. Padmanabhan, S. Palanisamy, Energy Conv. Manag., 59, (2012)

23. W. H. Azmi, M.Z. Sharif, T.M. Yusof, M. Rizalman, A.A.M. Redhwan, Renew. Sust. Energy Revi., 69, (2017)

24. D. Yang, B. Sun, H. Li, Y. Fan, Int. J. Refrig., 56, (2015)

25. B. Sun, D. Yang, Int. J. Heat Mass Transf., 64, (2013)

26. A. Bejan, Entropy generation through heat and fluid flow, New York: Wiley. (1982)

27. P. K. Singh, K. B. Anoop, T. Sundararajan, S. K. Das, Int. J. Heat Mass Transf., 53, (2010)

28. J. Li, C. Kleinstreuer, J. Heat Transfer, 132, (2010)

29. M. Moghaddami, A. Mohammadzade, S. A. Varzane-Esfehani, Energy Conv. Manag., 52, (2011)

30. K.Y. Leong, R. Saidur, T. M. I. Mahlia, Y. H. Yau, Int. Commu. Heat Mass Transf, 39, (2012)

31. V. Anand, Energy, 93, (2015)

32. A. Ebrahimi, F. Rikhtegar, A. Sabaghan, E. Roohi, Energy, 101, (2016)

33. G. Ibáñez, A. López, J. Pantoja, J. Moreira, Int. J. Heat Mass Transf., 100 , (2016)

34. E. Granryd, Int. J. Refrigeration, 24, (2001)

35. B. Palm, Int. J. Refrigeration, 31, (2008)

36. J. M. Calm, G. C. Hourahan, Heat. Pip. Air Cond. Eng, 79, (2007)

37. V. Bianco, F. Chiacchio, O. Manca, S. Nardini, App. Therm. Eng., 29, (2009)

38. M. Akbari, N. Galanis, A. Behzadmehr, Int. J. Heat Fluid Flow, 37, (2012)

39. B. H. Salman, H. A. Mohammed, A. Kherbeet, Heat Transf. Asian Research, 45, (2016) 